\title{
Experimental Simulation of High Enthalpy Planetary Entries
}

\author{
G. Herdrich*, M. Fertig and S. Löhle
}

Institut für Raumfahrtsysteme (IRS), University of Stuttgart, Pfaffenwaldring 31, D-70569 Stuttgart, Germany

\begin{abstract}
For the current exploration programs high enthalpy landing missions are foreseen. It is rather difficult to simulate the corresponding enthalpies with steady state facilities. For the case of sample return missions such as Genesis, STARDUST or Hayabusa hyperbolic entries require maximum enthalpies of about $80 \mathrm{MJ} / \mathrm{kg}$. Atmospheric entry parameters of relevance were derived with the model of Allan and Eggers which was developed for ballistic capsules. The model was then extended by validated engineering equations for both convective and radiation heat flux. In addition, the integral for the total convective heat load and the upper Gamma function integrals for the integral radiation heat load were derived and solved. This provides the potential to assess parameters relevant within the test philosophy such as e.g. the test duration while having a material sample exposed e.g. under maximum heat flux conditions to the plasma. In this context it is shown that the high specific enthalpies can be reproduced using e.g. magnetoplasmadynamically driven plasma wind tunnels. Atmospheric entry missions at the planets, however, are accompanied by initial kinetic energies for the spacecraft that are at least in the order of half of the second power of the first cosmic velocity of the related planet. Corresponding specific enthalpies e.g. for the Jovian entry are by a factor of almost 8 higher than the enthalpies experienced within a hyperbolic Earth entry. The paper discusses potential facilities that can be used for the investigation of these entry missions.
\end{abstract}

Keywords: Ablator, heat shield mass, high enthalpy atmospheric entry, plasma wind tunnel (PWK).

\section{INTRODUCTION}

Exploration programs aiming for landing missions on the solar system's planets were successfully performed by NASA. Numerous scientific missions have been launched to the inner and outer solar system. Among them the PioneerVenus probe mission, the Galileo probe to Jupiter [1] and the present sample return missions Genesis, STARDUST and Hayabusa belong to the most challenging e.g. with respect to the required atmospheric entry manoeuvres. The list could be continued within the frame of programs such as Aurora where demanding atmospheric manoeuvres such as e.g. hyperbolic re-entries are required for the planned Mars sample return missions.

Generally speaking, the first step towards the experimental simulation of atmospheric entries is in the accomplishment of the related specific enthalpies. For entries from circular orbit the initial entry speed is in the order of the $1^{\text {st }}$ cosmic velocity:

$v_{1}=\sqrt{\frac{G m_{\text {body }}}{r_{\text {body }}}}$.

It is a simple train of thoughts to provide the initial mass specific enthalpy which is just $1 / 2 \cdot v_{1}^{2}$.

Fig. (1) shows the result of this consideration. Obviously orders of magnitude are passed through such that a comparison of a low Earth orbit reentry, which is accompanied by an initial specific enthalpy of $32 \mathrm{MJ} / \mathrm{kg}$,

*Address correspondence to this author at the Institut für Raumfahrtsysteme (IRS), University of Stuttgart, Pfaffenwaldring 31, D-70569 Stuttgart, Germany; E-mail: herdrich@irs.uni-stuttgart.de with a Jovian entry, associated with a specific enthalpy of more than $1 \mathrm{GJ} / \mathrm{kg}$, shows both the wide range that has to be covered and the extensive requirements that must be met by facilities that simulate such entry missions. The value for Jupiter, however, is a result for an equatorial entry where the relative speed of the rotating atmosphere is subtracted. Entries other than equatorial in turn would come along with up to $1.8 \mathrm{GJ} / \mathrm{kg}$ corresponding to a maximum of $60 \mathrm{~km} / \mathrm{s}$ as initial entry velocity.

For the entry missions at the giant planets this means that the interaction between the massive ablation and the radiation is neither well understood nor satisfactorily modeled. A decisive improvement of knowledge and understanding would come from adequate ground testing facilities. The lack of these facilities prevents new ablative thermal protection materials from being developed and qualified. Additionally, the assessment of different atmospheres is difficult as long as experimental data and, as a consequence, reliable models are rare. Such a situation arose for the Titan entry mission of Huygens. Here, the qualification of the AQ-60 heat shield was performed successfully using the IRS Magnetoplasmadynamic (MPD) plasma wind tunnel PWK2. (PWK is the German abbreviation for plasma wind tunnel.) The experimental data obtained were a basis for first simple models on the time dependant recession of the ablation material in a nitrogen / methane atmosphere [2]. Additionally, information was gathered on the radiation [3] as e. g. for carbon containing gases which arise depending on atmospheric constituents or from ablation of the heat shield the radiation heat flux is not negligible either.

A similar consideration can be made for sample return missions where the initial hyperbolic (often referred to as 


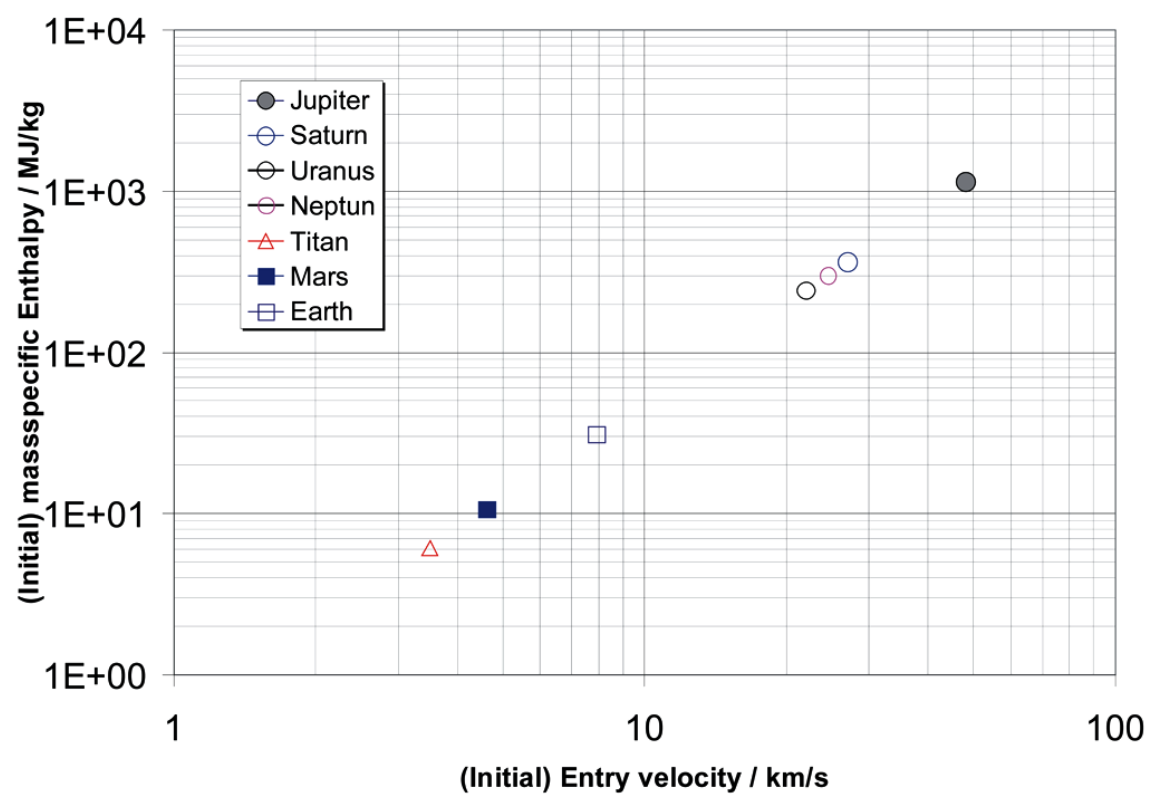

Fig. (1). Initial entry velocity and specific enthalpies for entries at relevant celestial bodies.

super orbit) entry velocity is in the order of the $2^{\text {nd }}$ cosmic velocity as a lower limit (related to Earth if bodies come from infinity where they have often been rather slow), i.e. $v_{2}=\sqrt{ } 2 \cdot v_{1}$ and the corresponding initial mass specific enthalpy is $2 \cdot v_{l}^{2}$. For STARDUST this lead to an initial entry velocity of $12.8 \mathrm{~km} / \mathrm{s}$ which corresponds to $82 \mathrm{MJ} / \mathrm{kg}$.

Similar to the high speed entries at the giant planets new and rather unknown effects must be taken into account. Among those there are e.g. the ionization processes and the increasing radiation heat fluxes that can become a significant portion of the total heat flux. Moreover, those heat fluxes are in the range between some $\mathrm{MW} / \mathrm{m}^{2}$ and several $10 \mathrm{MW} / \mathrm{m}^{2}$ leading to very stringent requirements to be fulfilled by the thermal protection system of the vehicle. STARDUST a mission in which IRS participated within a measurement campaign on an airborne mission using a DC8 aeroplane is an example. Here, spectroscopic measurements were successfully taken during the hyperbolic re-entry of STARDUST using a set-up flown on the aeroplane in cooperation with NASA, SETI (Search for Extraterrestrial Intelligence) Institute, DLR (German Aerospace Centre) and the Steinbeis Transfer Centre Plasma and Space Technology (StC PRT) [4].

The trajectory parameters are shown in Fig. (2). It can be seen that the maximum specific enthalpy is in the order of $80 \mathrm{MJ} / \mathrm{kg}$ along a wide range of the trajectory. STARDUST itself is the fastest artificial object that entered into Earth's atmosphere $(v=12.8 \mathrm{~km} / \mathrm{s})$ ever. In Fig. (3) enthalpy envelopes of the IRS plasma wind tunnels are shown together with typical entry missions.

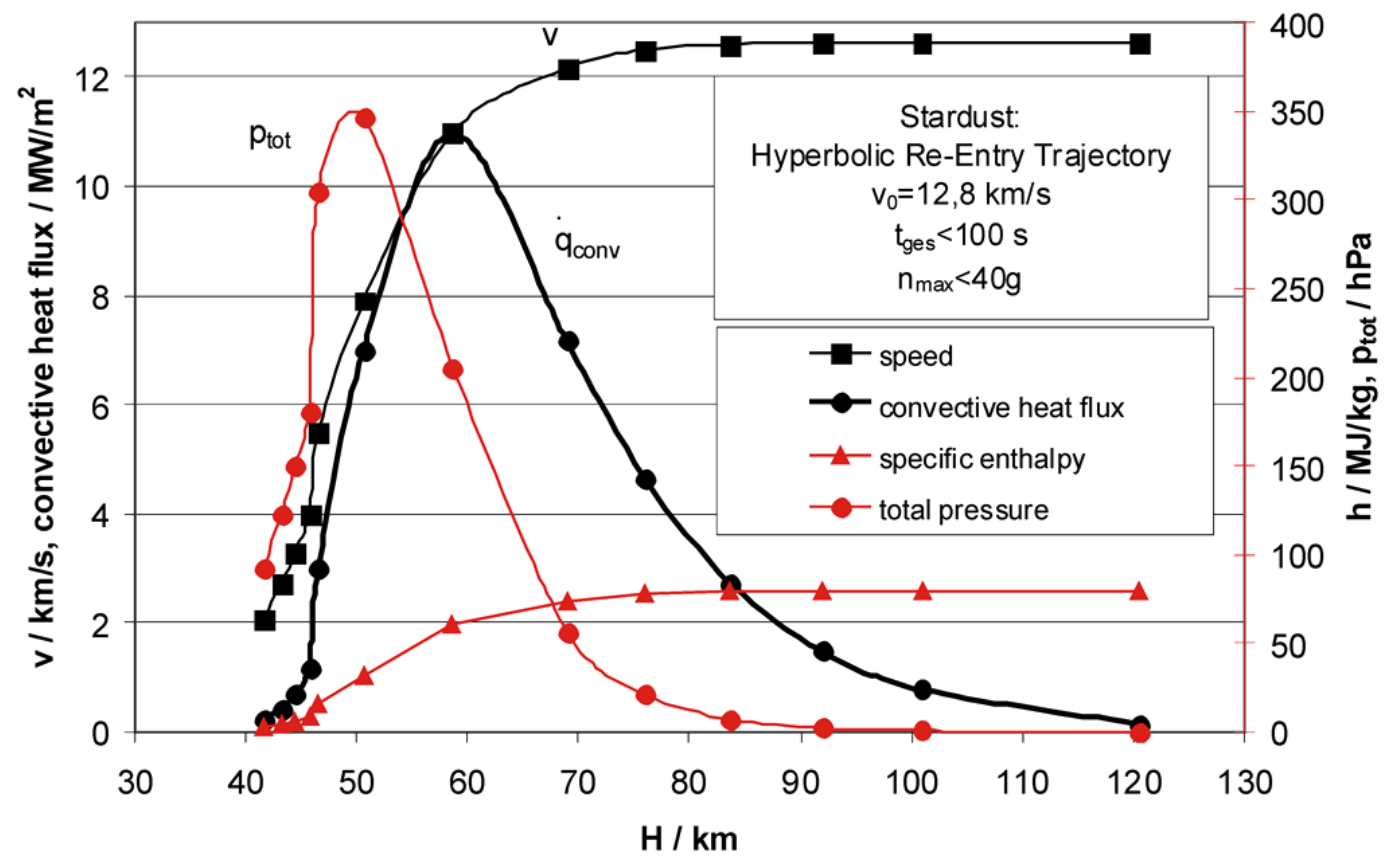

Fig. (2). Trajectory parameter of STARDUST. 


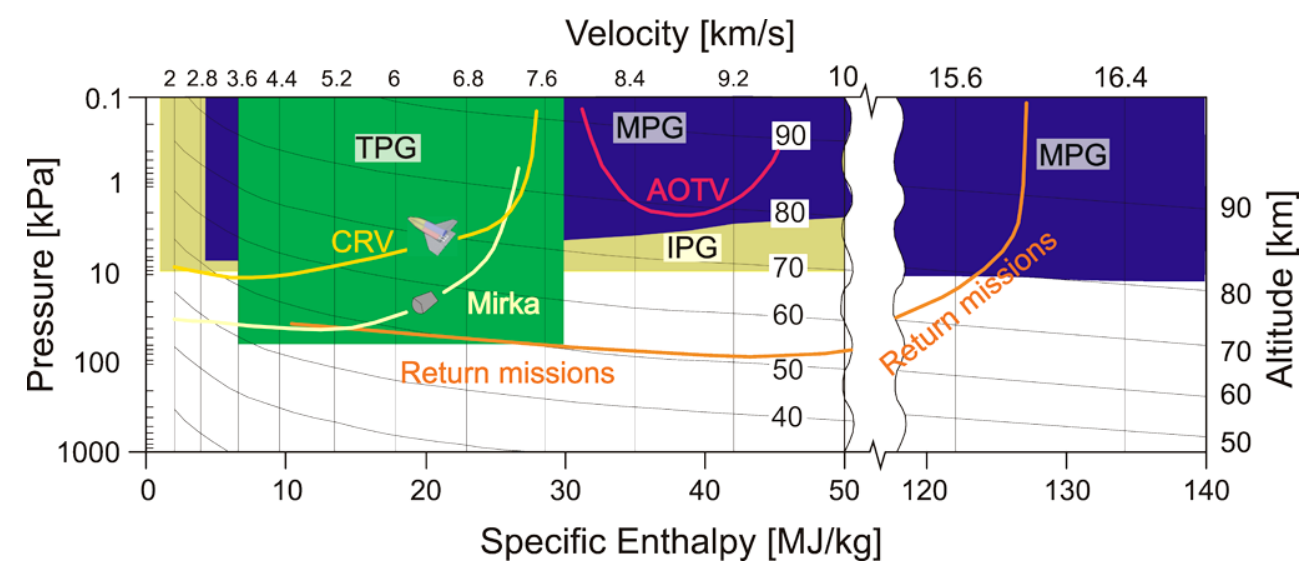

Fig. (3). Enthalpy envelopes of IRS PWT together with representative entry missions.

A representative hyperbolic re-entry mission is also shown in Fig. (3). It can be seen that the very high enthalpies can be covered by MPD-driven PWK1 and PWK2 and at least partly by the inductively driven PWK3.

This consideration fits well as long as the enthalpy similarity is taken into account. But it is rather difficult to achieve the corresponding pressures. However, for a more detailed investigation boundary layer similarities have to be considered.

From the experience of the flown missions and the adaption of semi-empirical equations to the best reliable data from both modelling and flight experiments $[5,6]$ some statements can be made that allow for the information in Fig. (4). One related semi-empirical model is

$\dot{q}_{S}=\frac{c}{\sqrt{R_{N}}} \rho^{s} v^{x}$

for the convective heat flux. This equation was developed by Lees [7]. Here, $c$ is a constant value; $R_{N}$ is the nose radius in the stagnation region, $\rho$ the density and $\mathrm{v}$ the velocity of the vehicle. The constants $\mathrm{c}, \mathrm{s}$ and $\mathrm{x}$ depend on the boundary layer flow type. For earth entry e.g. c is $1,705 \cdot 10^{-4} \mathrm{~W} \cdot \mathrm{s}^{3} \cdot \mathrm{kg}^{-}$ $0,5 \cdot \mathrm{m}^{-1}$ with $s=0,5$ and $x=3$ assuming laminar flow in the stagnation boundary layer. Analogous equations were developed for the radiation heat fluxes. The best known are from Tauber and Sutton [8] and Detra and Hidalgo [9]. The latter is shown here as the dependence to the already discussed parameter is more evident:

$\dot{q}_{r a d}=a \cdot R_{N} \cdot\left(\frac{v_{\infty}}{b}\right)^{8,5}\left(\frac{\rho_{\infty}}{\rho_{0}}\right)^{1,6}$.

Here, $a$ and $b$ are constants that can be specifically derived for the different entry environments. The infinity index signifies parameter in the incident flow. The index " 0 " means that the parameter is related to zero-level. From the consideration of the two equations (1) and (2) it can be easily seen that the resulting loads are contrarian with respect to the radii of the stagnation thermal protection system. With equation (1) the convective heat flux decreases with increasing radius while equation (2). In addition, both the strong dependence of equation (2) with respect to the velocity and also the stronger dependence concerning the density can be seen.
This can be confirmed by the illustration of the different heat fluxes in Fig. (4). For the LEO (low Earth orbit) reentries radiation heat fluxes are negligible, with Mars Pathfinder radiation becomes more evident due to the carbonaceous atmosphere of Mars. Of course, both heat flux fractions increase with increasing velocity as can be seen for Apollo which enters on a hyperbolic path. The same applies to Mars Sample Return (Aurora) while the radiation becomes even larger for the Venus entry of Pioneer-probes at more than $11 \mathrm{~km} / \mathrm{s}$ also due to the high densities compared to Mars. This is then the first time when the radiation fraction becomes larger than the convective heat flux, which is also the case for Galileo where a total of more than $500 \mathrm{MW} / \mathrm{m}^{2}$ is reached.

Finally, the majority of the scientific missions have been equipped with ablation heat shields due to the associated high enthalpies starting from $62 \mathrm{MJ} / \mathrm{kg}$ (Apollo). The present report will outline that steady state facilities to cope with such enthalpies exist e.g. in the form of MPD plasma facilities. For missions to the outer solar system planets, enthalpies have to be created that are beyond present capabilities with the exception of the Giant Planet Facility which, unfortunately, has been disassembled.

Within the field of reusable thermal protection systems, certain aspects of higher enthalpy have to be considered. Among those the heat flux limit and the oxidation regime limit. However, related specific enthalpies are small compared to the above mentioned values and the ongoing processes are better understood [11].

\section{POINT OF DEPARTURE}

The problem of atmospheric entry deals with complex non-equilibrium effects where the plasma properties, the interaction of the plasma with thermal protection material, the behaviour of the material and the structural coupling have to be considered. All of the research fields mentioned demand very detailed theoretical and experimental investigation and research work. Therefore, this section has not the ambition to cover them on such a detailed level. It is rather a motivation to provide engineering equations that allow statements for different scientific entry and/or landing missions which in turn partially forms the requirements for necessary ground testing facilities. This again impacts their design. 


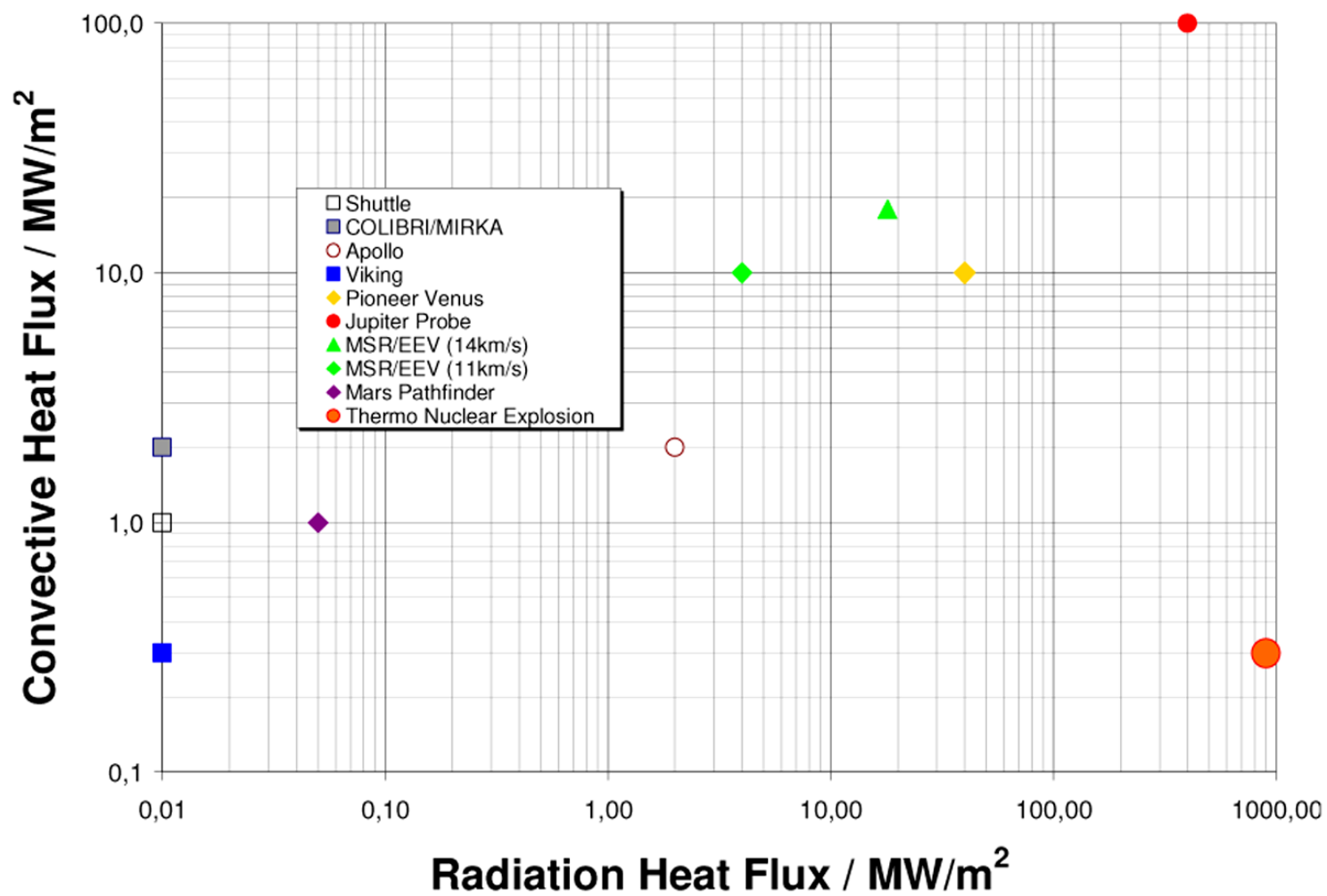

Fig. (4). Heating environments $[1,10]$.

Particularly, the Allan/Eggers model is highlighted [12]. This report originally provided a simplified analysis of the velocity and deceleration history of missiles that enter the atmosphere at high supersonic speeds. The model itself is of an algebraic nature due to the fact that the gravitational force is small compared to the drag force which in turn allows the explicit solution of the derived differential equation. The motion analysis in reference [12] is combined with a coarse derivation of the total heat input while the results shown here represent an extension of the aforementioned model as the insertion of the existing heat flux equations, i.e. Eqs. 1 and 2, makes it possible to estimate both convective and radiation heat flux. Moreover, the integral convective and radiation heat loads and the total heat load are calculated. The values of those parameters in turn have major consequences for the thermal protection system (TPS) mass allocation which is derived on basis of literature values from existing atmospheric entry missions, see Fig. (5) below. A detailed derivation of the announced equations can be found in reference [13].

Fig. (5) shows the relation between total heat flux and TPS mass fraction on basis of the data found in $[1,14]$. It outlines two major standpoints: Particularly, the challenging missions such as the hyperbolic re-entries and the entry missions to planets of high mass motivate the desire to optimize the TPS aiming for mass savings e.g. for the sake of higher scientific payload masses. The second aspect accompanies this observation: The most challenging missions i.e. the Pioneer Venus Probe missions and the Jupiter probe Galileo were performed using the high density versions of the American FM5055 Phenolic impregnated carbon ablator which on the one hand is the most efficient ablation material, however, the material is derived from developments that are more than 20 years old and the procurement is at present doubtful. Consequently, the development of new, more efficient materials is justified. Such developments, nevertheless, have to be subject to extensive experimental investigations using adequate facilities. This observation was also made by Laub et al. where even a corridor of potential mass saving was shown in a Figure corresponding to Fig. (5), an approach which the authors of this paper do not dare [1]. The graph can also be considered as a means of a tool to preliminarily estimate the needed TPS mass fraction. The dashed regression curve has the numerical equation $m_{T P S} / m_{\text {total }} \approx 0.011 \cdot \sqrt{ }\left(Q_{\text {tot }} /\left(1 \mathrm{MJ} / \mathrm{m}^{2}\right)\right.$.

A similar function has already been derived by Laub and Venkatapathy [1]. However, for the sake of completeness and clarity the data base in Fig. (5) is extended and a simpler numerical equation is used.

A two-dimensional approach is considered for the following model, i.e. the plane two-dimensional Atmospheric entry of a ballistic capsule with constant ballistic coefficient. For the atmosphere an exponential profile is used while the flight path angle is considered constant.

The two equations in the two directions $\mathrm{x}$ and $\mathrm{y}$ become only one equation when the trigonometric dependency of $\theta$ is inserted and in high altitudes the gravity force is much smaller than the friction forces:

$\frac{d v}{d t}=-\frac{1}{2} \frac{\rho}{\beta} v^{2}$

Here, $\beta=m /\left(C_{D} \bullet A_{\text {ref }}\right)$ is the ballistic coefficient. The ballistic coefficient is of high importance for vehicle behavior: Vehicles with high $\beta$ experience the reduction of 


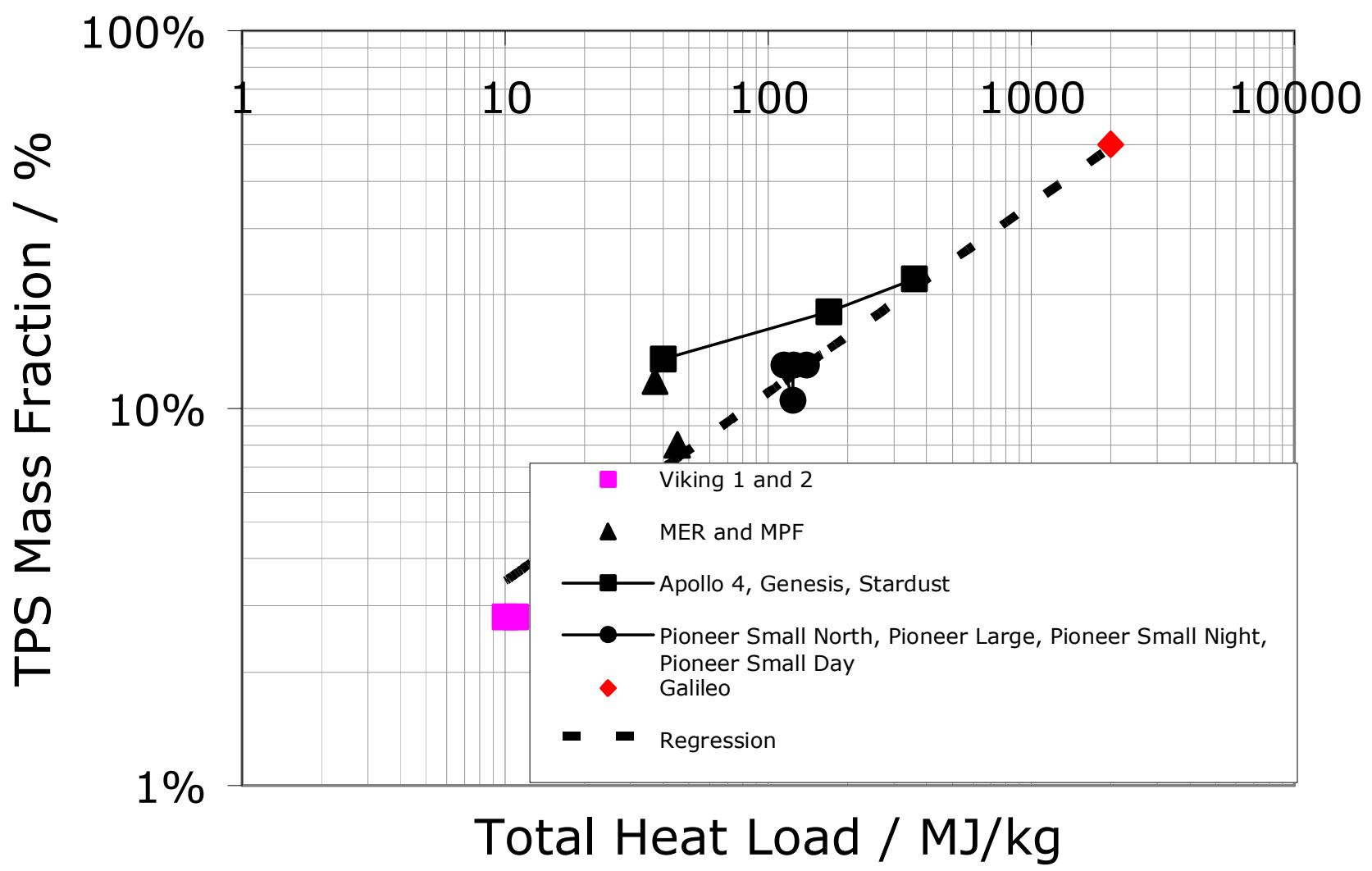

Fig. (5). TPS mass fraction for different capsules over total heat load after [1, 14].

velocity rather slowly such that they may impact the surface may even at higher speed (a worse case scenario also e.g. for meteor impacts, or the situation of a missile). For very low $\beta$ the vehicle in turn reduces velocity in high altitudes even in the lower density atmosphere regions. This leads to a reduction of the heating (e.g. Archimedes Mars Balloon Mission).

With $v \bullet d v \cdot \sin (\theta) / d y=-d v / d t$, assuming $h>>h_{\text {ref }}$ and integrating one gets:

$\frac{d v}{v}=\frac{1}{2} \frac{\rho_{0}}{\beta \sin (\theta)} \exp \left(\frac{-h}{h_{r e f}}\right) d h$.

Let $\exp \left(-h / h_{\text {ref }}\right)$ expressed with K. Using $h>>h_{\text {ref }}$ one gets:

$\frac{v(h)}{v_{E}}=\exp \left(\frac{-\rho_{0} h_{r e f}}{2 \beta \sin (\theta)} K\right)$,

which is the equation that describes the dependency of $v(h)$. This directly delivers the load factor using Eq. 4:

$n=\frac{-v_{E}^{2} \rho_{0}}{2 \beta a_{0}} K \exp \left(\frac{-\rho_{0} h_{r e f}}{\beta \sin (\theta)} K\right)$.

The maximum of $\mathrm{n}\left(C=-\rho_{0} \bullet h_{r e f} f(\beta \bullet \sin (\theta))\right)$ is at:

$h=h_{\text {ref }} \ln (-C)$.

The corresponding maximum value $\mathrm{n}_{\max }$ is:

$$
n_{\max }=-\frac{1}{2 e} \frac{v_{E}^{2} \sin (\theta)}{a_{0} h_{r e f}} .
$$

Considering Eq. 9 some major observations become evident: The maximum load $\mathrm{n}_{\max }$ does not depend on $\beta$. If we consider comparable entry angles, the hyperbolic atmospheric entry's load factor is roughly the double of the one resulting from a LEO atmospheric entry $\left(2^{\text {nd }}\right.$ power of the ratio of the $2^{\text {nd }}$ to the $1^{\text {st }}$ cosmic velocity).

The calculation of the specific enthalpy is rather easy as it is equal to the mass specific kinetic energy of the vehicle, $h=1 / 2 \bullet v^{2}$. For constant $\beta \cdot \sin (\theta)$, the specific enthalpies roughly double in value compared to a circular low orbit if a super-orbital entry is assumed.

Analogously, the equations for dynamic and total pressure can be derived $\left(p_{\text {dyn, ref }}=1 / 2 \bullet \rho_{0} \bullet v_{E}^{2}\right)$

$p_{d y n}=\frac{1}{2} \rho v^{2}(h)=p_{d y n, r e f} K \exp \left(\frac{-\rho_{0} h_{r e f}}{\beta \sin (\theta)} K\right)$.

A relative maximum of the dynamic pressure can be derived; however, this may be of greater importance for the total pressure which is

$$
p_{\text {total }}=\left[p_{0}+p_{d y n, r e f} \exp \left(\frac{-\rho_{0} h_{r e f}}{\beta \sin (\theta)} K\right)\right] K \text {. }
$$

The relative maximum of $\mathrm{p}_{\text {total }}$ is at: 


$$
h_{p_{\text {toutl, } \max }} \approx h_{\text {ref }} \ln (-b)=h_{n_{\max }} .
$$

The corresponding pressure value is:

$$
p_{\text {total,max }} \approx \beta \sin (\theta) a_{0}\left(1+\frac{\rho_{0} v_{E}^{2}}{2 e p_{0}}\right) .
$$

In fact, this maximum is often smaller than $\mathrm{p}_{0}$ while the maximum at the boundary $h=0 \mathrm{~m}$ is from the mathematical point of view larger than $\mathrm{p}_{0}$. However, typical landing missions aim for $p_{\text {total }}=p_{0}$ at $h=0 \mathrm{~m}$ as it means that the vehicle would crash into ground if it had a significant velocity at zero-level. This aspect, however, is triggered via the ballistic coefficient and also slightly via $\theta$ as the pressure history depends on this value. Vehicles with large $\beta$ quasi hit the ground while small $\beta$ vehicles decelerate more effectively.

Using Eqs. (1) and (4), the history of the convective heat flux can be derived:

$\dot{q}_{\text {conv }}=c v_{E}^{3} \sqrt{\frac{\rho_{0}}{R_{N}} K} \exp \left(\frac{-3 \rho_{0} h_{r e f}}{2 \beta \sin (\theta)} K\right)$. flux:

This equation has a maximum i.e. the maximum heat

$$
\dot{q}_{c o n v, \text { max }}=c v_{E}^{3} \sqrt{\frac{\beta \sin (\theta)}{3 e h_{r e f} R_{N}}} .
$$

An analogous procedure can be performed with the radiation heat flux:

$$
\begin{aligned}
& \dot{q}_{\text {rad }}=\frac{a}{b^{8,5}} R_{N} v_{E}^{8,5} K^{1,6} \exp \left(\frac{-17 \rho_{0} h_{r e f}}{4 \beta \sin (\theta)} K\right), \\
& \dot{q}_{\text {rad, } \max }=a R_{N}\left(\frac{v_{E}}{b}\right)^{8,5}\left(\frac{32 \beta \sin (\theta)}{85 e \rho_{0} h_{r e f}}\right)^{1,6},
\end{aligned}
$$

Except for the nose radius, all other dependencies in Eqs. 15 and 17 are qualitatively of the same nature. However, the powers in the equation for the maximum radiation heat flux are significantly higher. Particularly, the $8,5^{\text {th }}$ power of the velocity is of high importance.

With this information the integral heat loads can be derived. The result for the convective heat load is:

$$
\begin{aligned}
Q_{\text {conv }} & =\int \frac{\dot{q}_{\text {conv }}}{v_{y}} d h \\
& =\frac{-c v_{E}^{2}}{\sin (\theta)} \sqrt{\frac{\rho_{0}}{R_{N}}} \int \sqrt{K} \exp \left(\frac{-\rho_{0} h_{r e f}}{\beta \sin (\theta)} K\right) d h .
\end{aligned}
$$

The solution is a bit consuming and is shown in the following. For the sake of clarity only the integral in Equ. (18) with certain substitutions that can be derived by the reader by a comparison with Equ. (18) is considered. This integral has to be solved using the substitution $u_{I}=K^{1 / 2}$. With this $d u_{1} / d h=-u_{1} /\left(2 \bullet h_{\text {ref }}\right)$ follows. For a further simplification mind that $\left(\rho_{0} \bullet h_{r e f}\right) /(\beta \bullet \sin (\theta))$ is expressed by C. The integral of Equ. (18) and its solution then become

$$
\begin{aligned}
-2 h_{r e f} \int e^{-C u_{1}^{2}} d u_{1} & =\left[-h_{r e f} \sqrt{\frac{\pi}{C}} \operatorname{erf}\left(\sqrt{C} u_{1}\right)\right]_{e^{0}}^{\sqrt{K}} \\
& =-h_{\text {ref }} \sqrt{\frac{\pi}{C}}[\operatorname{erf}(\sqrt{C K})-\operatorname{erf}(\sqrt{C})]
\end{aligned}
$$

an error function. After re-substituting the diverse constants one gets:

$$
Q_{c o n v}=c v_{E}^{2} \sqrt{\frac{\pi h_{r e f} \beta}{\sin (\theta) R_{N}}}[\operatorname{erf}(\sqrt{C K})-\operatorname{erf}(\sqrt{C})] .
$$

This equation already represents the solution of the problem for the integral convective heat load. However, to satisfy an improved understanding the following considerations can be made:

- $\quad$ The upper limit for $\mathrm{h}$ is very large compared to $\mathrm{h}_{\text {ref }}$. For the first error function in Equ. (20) this leads to $\operatorname{erf}(0)$ which is 0 .

- The argument of the second error function is quite large and, therefore, the error function approximates 1.

Therefore, Equ. (20) can be very well approximated by:

$Q_{c o n v}=\int \frac{\dot{q}_{c o n v}}{v_{y}} d h \approx c v_{E}^{2} \sqrt{\frac{\pi h_{r e f} \beta}{\sin (\theta) R_{N}}}$.

For the radiation case this leads to

$$
\int \frac{\dot{q}_{r a d}}{v_{y}} d h=-\frac{a}{b^{8,5}} \frac{R_{N} v_{E}^{15 / 2}}{\sin (\theta)} \int e^{\frac{-15}{4} C K} K^{1,6} d h .
$$

The solution is even more complex than the solution for the convective case. Again, for the sake of clarity, only the integral in Eq. (22) is considered in the following. For this the substitution $u_{2}=K^{1,6}$ is used leading to $d u_{2} / d h=$ $1,6 \bullet u_{2} \bullet / h_{r e f}$. The integral and its (first step) solution then become

$$
\begin{aligned}
& \int u_{2} e^{-C u_{2}^{5 / 8}} \frac{-h_{r e f}}{1,6 u_{2}} d u_{2}=-\frac{h_{r e f}}{1,6} \int e^{-C u_{2}^{5 / 8}} d u_{2} \\
& =\left[\frac{-h_{r e f} u_{2}^{3 / 8}}{5 C}\left(\frac{-5}{e^{c u_{2}^{5 / 8}}}-\frac{3 \Gamma\left(3 / 5, C u_{2}^{5 / 8}\right)}{\left(C u_{2}^{5 / 8}\right)^{3 / 5}}\right)\right]_{e^{0}}^{-\frac{1,6 h}{h_{r e f}}} .
\end{aligned}
$$

Here, $\Gamma(a, b)$ is an incomplete upper Gamma function which is defined as

$$
\Gamma(a, x)=\int_{x}^{\infty} t^{a-1} e^{-t} d t
$$

To have a traceability of this derivation the gamma functions are considered in detail. In fact, an integration from $e^{0}=1$ to 0 (h is very large compared with $\mathrm{h}_{\text {ref }}$ ). Therefore, $\Gamma(0.6,0) \approx 1,48$ and $\Gamma\left(0.6, C_{\text {Earth }}\right)$ are obtained respectively. Here, $C_{E a r t h}$ is $-15 / 4 \bullet C$ and for the analysis of the second integral values for the Earth case have been used to analyse the order of magnitude $b$ can have. Using this, 
$\Gamma\left(0.6, C_{E a r t h}\right)$ becomes approximately 0 such that Equ. (23) can be evaluated leading to the approximate result for the radiation based total integral head lead:

$Q_{\text {rad }} \approx \frac{107,4 a}{10^{3} b^{8,5}} \frac{R_{N} h_{r e f} v_{E}^{15}}{\sin (\theta)}\left(\frac{\beta \sin (\theta)}{\rho_{0} h_{r e f}}\right)^{8 / 5}$.

The total heat load is the sum of Eqs. 21 and 25. Together with Fig. (5) a primitive engineering tool is now provided for the statement of the dependencies of the TPS mass fraction and its approximate calculation. Of importance is that the model in its present form enables both the derivation of entry trajectory parameters for ballistic capsules including radiation heat flux and total heat flux and, in addition, the assessment of requirements within the test philosophy e.g. for an ablative material sample in a plasma facility. This is not only referred to parameters such as heat flux and total pressure but also to constraints such as the test duration. Having a material sample exposed to a constant plasma condition at maximum heat flux for example could now be combined with a test duration derived from the total integral heat load divided by this heat flux.

As an overall statement the following aspects have to be realized:

Aiming for more challenging missions such as multiple probe missions entering Jupiter's atmosphere along trajectories that are not in the equatorial plane leads to a maximum increase of the entry speed of $25 \%$ compared to Galileo. This in turn would increase the total radiation based heat load by a factor of 5.33 if the remaining parameters in Eq. 21 stay the same. This again increased the TPS mass fraction by a factor of 2.3 leading to a TPS mass fraction higher than $100 \%$ which, of course, is senseless but shows that there is the limit of the existing ablation entry materials within this scenario.

The second aspect is of a rather scientific nature: It is shown by the data base depicted in Fig. (5) that it is most desirable to have new, more advanced and improved materials allowing a decrease of the required TPS mass fraction. This in turn motivates development activities for which adequate test facilities are a necessity. Again, this has also to be seen with the background of appropriate test conditions as $h_{\text {ref }}$ and $\rho_{0}$ for example take into account the celestial body's atmospheric properties while the $\mathrm{v}_{\mathrm{E}}$ considers the mass of the celestial body. The consideration of the required facilities, therefore, must account for the needed entry conditions as e.g. for the mass specific enthalpies. Consequently, there may be not just one facility but rather different test systems for the different mission related entry conditions.

Technically spoken, the Apollo ablation material AVCOAT 5026-39 is no longer available and the same applies to the less performing DC-325 (Gemini), which has a lower performance. The FM 5055 of the Pioneer Probes and Galileo may not be longer available as there is only a small amount of the heritage rayon precursor left which had been being produced during the 1970s [15]. In conclusion, the situation in the USA for the high pressure and high total heat loads is such that the required materials are either outdated or the availability is critical or both.
In Europe the situation is different but still similar: Within programs such as Aurora rather modern materials are investigated. In addition, the silica fiber based AQ60 has its heritage due to the successful Titan Huygens mission $[2,3]$. Moreover, an extensive data base has been derived from the experience in missile technology both in France and Great Britain. However, these data are mostly not accessible and the running space programs in Europe are partially starting from scratch. In addition, there is, of course, new aspects that come from both the basic design of entry vehicles (blunt bodies instead of slender bodies) and requirements due to the environmental conditions e.g. the different pressure ranges (hyperbolic re-entries) and the unknown significance of the particles in the Mars atmosphere with respect to the ablator's behavior: However, for the previous aspects flight experience was gained with the Aerothermodynamic Reentry Demonstrator (ARD, equipped with Norcoat Korc) and a certain relationship is also established with MIRKA $[16,17]$. Nevertheless, for the hyperbolic re-entries facilities are required, while it has to be understood that the different facilities can only cover different single aspects of a hyperbolic entry. The MPD facility PWK2 that was also used for the Titan Huygens AQ60 qualification [3] belongs to the only facilities in Europe that can cover the local specific enthalpies that are in the order of up to $80 \mathrm{MJ} / \mathrm{kg}$ for the present hyperbolic re-entries. The measured spectroscopic data of STARDUST are inserted into a 3,5 year post-flight analysis program together with ESA (European Space Agency) [4]. Here, IRS participated successfully with two different spectroscopic measurement systems. However, the pressure of such facilities is limited to a maximum of $5 \mathrm{kPa}$ such that the inclusion of numerical tools is mandatory [18]. The data and the program itself will be of high importance for the currently ongoing Aurora program as the hyperbolic re-entry of the Mars sample return capsule is comparable to the STARDUST re-entry. With the Giant Planet Facility at NASA Ames, however, high enthalpy conditions within a higher pressure range were carried out [19]. For Galileo e.g. conditions at heat flux levels around $200 \mathrm{MW} / \mathrm{m}^{2}$ at impact pressures of $0.3 \mathrm{MPa}$ were achieved [20]. Unfortunately, this facility was dismounted.

Extensive investigations in Europe were done using arcjet facilities in combination with powder feeders inserting the particles downstream into the plasma. However, these facilities suffer from the inertia of the particles with respect to the plasma jet velocity such that their velocity is roughly one order of magnitude too low. One-dimensional analysis shows that this problem may be reduced by adequately using inductively heated plasma facilities where the powder is inserted into the discharge zone allowing a longer acceleration track for them. These facilities by themselves have already been qualified for such operations [21, 22].

Table 1 gives an overview of the most important ablation materials, the corresponding entry missions and the initial entry velocity $\left(\mathrm{v}_{\mathrm{E}}\right)$ that were developed and applied in the past. A comparison in terms of challenge is feasible if the concerned mission is considered i.e. the most challenging atmospheric entry mission was Galileo, followed by the Venus entries (Pioneer), followed by STARDUST and other hyperbolic re-entries (Apollo) and then followed by the Earth entries from low Earth orbit (such as e.g. MIRKA or 
Gemini). However, this consideration does not take into account the differences in thermo-chemical load due to the different atmospheres.

Table 1. Overview of Most Important Ablation Cooling Materials, (almost) Historically Ordered

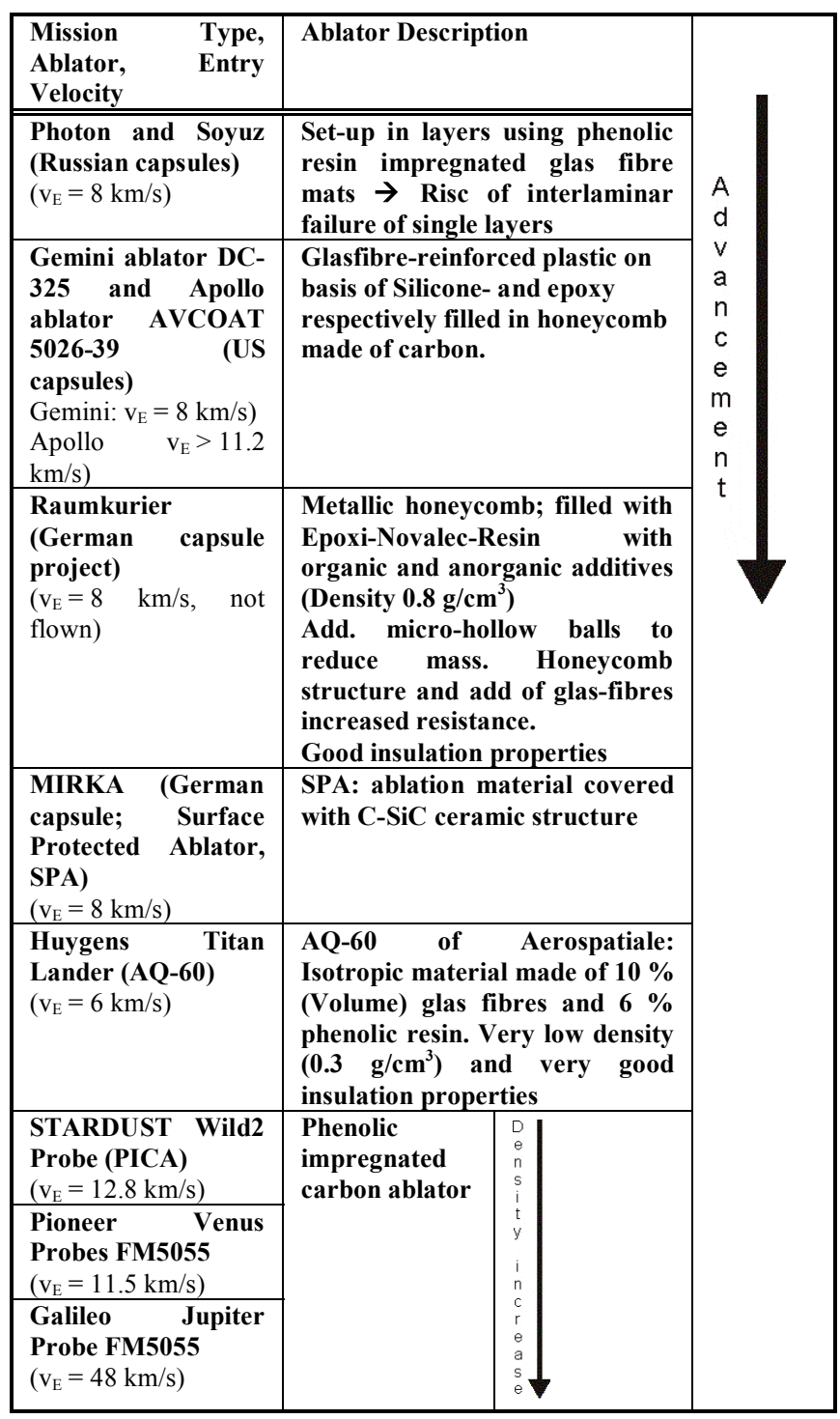

\section{HYPERBOLIC RE-ENTRIES: PWK-RD5 AND RD-7}

This section describes facilities at IRS that enable the simulation of hyperbolic re-entries such as performed by STARDUST. More detailed descriptions can also be found in [23].

\section{MPD RD5 and RD7}

As an example for high enthalpy facilities a photograph of the PWK 2 facility is shown in Fig. (6).

The vacuum tanks used for PWK 1 and 2 are 6 m-long steel tanks each with a diameter of $2 \mathrm{~m}$ and a double-wall cooling.
The PWK1 tank is closed with a hemispherical part which is connected to the vacuum system and protected against heat by water-cooled copper shields. On the other side the vacuum chamber can be opened by moving the plane cover plate on a guide rail. The plasma source is not located in the vacuum tank, but flanged on a conical part of the plate. The cone-shaped element of the end plate enables the plasma source to be fixed at that point. The whole plasma jet range is accessible by optical methods.

The facility is equipped with a 4-axis positioning system on which the different probes and the specimen support system can be mounted. This allows the simulation of parts of the reentry trajectories by automatically moving the specimen in different plasma flow regimes [24]. A certain point on a re-entry trajectory is defined by the ambient pressure, the axial distance to the generator, the arc current and the mass flow. Together, these values result in adequate enthalpy, total pressure and temperature or heat flux.

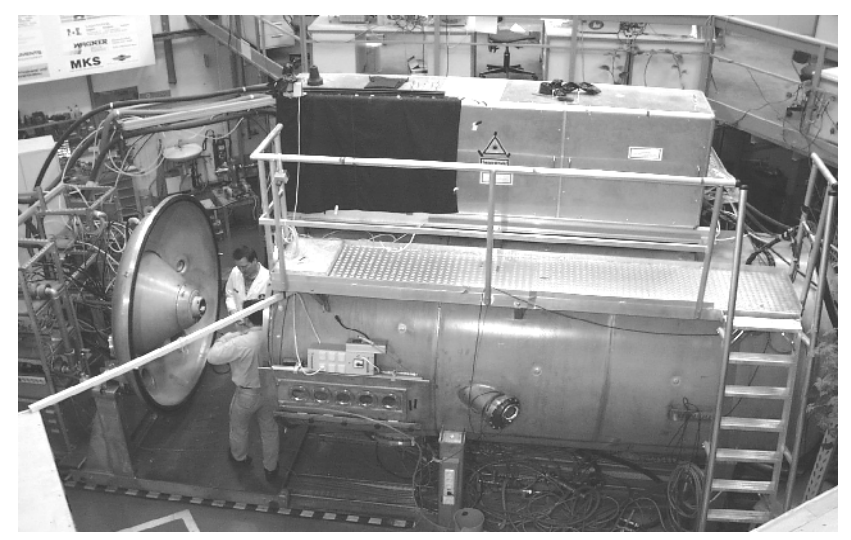

Fig. (6). Plasma wind tunnel PWK 2.

Optical glass windows allow pyrometric temperature measurements on the front side of the specimen at distances from the plasma source between about $50 \mathrm{~mm}$ and $1 \mathrm{~m}$. Moreover, optical measurements perpendicular to the plasma jet axis are possible through three movable flanges of three optical glasses each, which are located on both sides of the tank opposite each other and on the top, see Fig. (7).

The electric power is supplied by a current-regulated thyristor rectifier consisting of six identical units supplying $1 \mathrm{MW}$ each. These may be connected in series or parallel, thus varying the desired output level of current, voltage, and power. The current ripple is less than $0.5 \%$. The maximum current is $48 \mathrm{kA}$ supplied at $125 \mathrm{~V}$ and the maximum voltage is $6 \mathrm{kV}$ at a current of $1 \mathrm{kA}$.

Self-field MPGs of different sizes have been developed over the past decades at IRS; they are employed successfully in the IRS plasma wind tunnels PWK 1 and PWK 2.

The nozzle-type MPG plasma generators, see Fig. (7), consist of two coaxial electrodes, separated by water-cooled neutrodes. The nozzle exit, which is also a water-cooled segment, forms the anode. The cathode, made of $2 \%$ thoriated tungsten, is mounted in the center of the plenum chamber. 


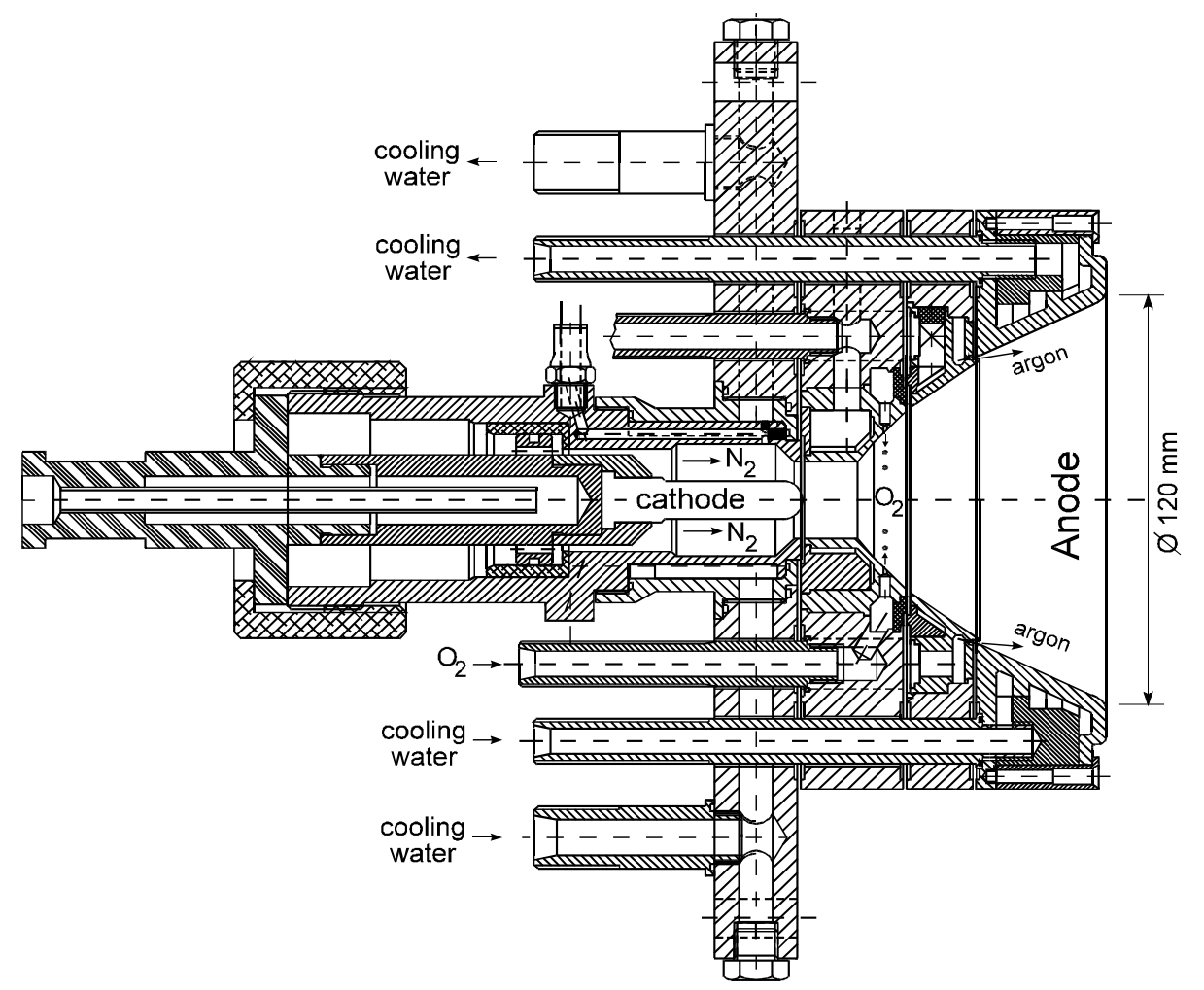

Fig. (7). Magnetoplasmadynamic generator RD5.

The arc is ignited by a Paschen breakdown. The current passes through the expansion nozzle from the cathode tip to the end of the nozzle. The test gas is dissociated and partly ionized. To avoid oxidation of the cathode, only the nitrogen component of the test gas is fed in along the cathode into the plenum chamber, heated up by the arc and accelerated partly by thermal expansion and partly by electromagnetic forces due to the self-induced magnetic field in the nozzle. The magnitude of the magnetic acceleration force strongly depends on the current level of operation. With this MPG, the oxygen needed for the duplication of high enthalpy air flows is fed in radially at a high velocity at the supersonic part of the nozzle but still within the arc region. The various gas injection points enable the operation of the MPG with different gas mixtures. So the investigation of entry maneuvers into the atmospheres of other celestial bodies such as Titan and Mars, containing $\mathrm{CH}_{4}$ and $\mathrm{CO}_{2}$, is possible.

Special efforts have been made to minimize the erosion of the plasma generator. To avoid a spotty arc attachment on the anode, which would cause a contamination of the plasma flow, a small amount of argon is injected tangentially along the anode contour. This method has been shown experimentally to eliminate anode erosion. Within the whole region of operation the only contaminating part of the MPG is the cathode. The $2 \%$ thoriated tungsten cathode reaches more than $3000 \mathrm{~K}$ during steady-state operation. The high temperature and the low work function of the cathode result in a diffuse arc attachment and, consequently, a very low cathode erosion rate at the order of sublimation. The very low cathode erosion results in operation periods of the MPG of hundreds of hours.

For the MPG generator RD5 with a nozzle exit diameter of $125 \mathrm{~mm}$, the mass flows are between $0.3 \mathrm{~g} / \mathrm{s}$ and $50 \mathrm{~g} / \mathrm{s}$ at current levels between $200 \mathrm{~A}$ to $4 \mathrm{kA}$ and power levels of $40 \mathrm{~kW}$ to $1 \mathrm{MW}$, while the average specific enthalpy $\bar{h}$ at the nozzle exit varies between $2 \mathrm{MJ} / \mathrm{kg}$ and $150 \mathrm{MJ} / \mathrm{kg}$.

For testing large TPS structures an MPG generator with an enlarged nozzle has been built. The nozzle diameter of RD7 is $320 \mathrm{~mm}$ (Fig. 10), which enables the investigation of TPS materials and sub-structures up to $400 \mathrm{~mm}$ in diameter.

For testing large TPS structures an MPG generator with an enlarged nozzle was built. The nozzle diameter of RD7 is $320 \mathrm{~mm}$ (Fig. 8), which enables the investi-gation of TPS materials and sub-structures up to $400 \mathrm{~mm}$ in diameter.

\section{Vacuum System}

A vacuum system is used to simulate pressures at altitudes up to $90 \mathrm{~km}$ (Earth). The pumping system consists of four stages: the first two stages are roots blowers, the third stage is a multiple slide valve type pump, and the last stage is a rotary vane type pump. The total suction power of the pumps amounts to $6000 \mathrm{~m}^{3} / \mathrm{h}$ at atmospheric pressure and reaches about $250000 \mathrm{~m}^{3} / \mathrm{h}$ at $10 \mathrm{~Pa}$ measured at the intake pipe of the system, which has a diameter of $1 \mathrm{~m}$. The base pressure of the system is $0.5 \mathrm{~Pa}$. The desired tank pressure can be adjusted between the best achievable vacuum and $100 \mathrm{kPa}$ by removing one or more pumps from the circuit and/or mixing additional air into the system close to the pumps.

\section{Examples of Investigation}

In PWK2 (RD5), for example, the qualification tests were carried out for the heat shield of Huygens for the entry into the atmosphere of Saturn's moon Titan [3]. The facility PWK1-RD7 was used for the high enthalpy SEPCORE ${ }^{\circledR}$ test 


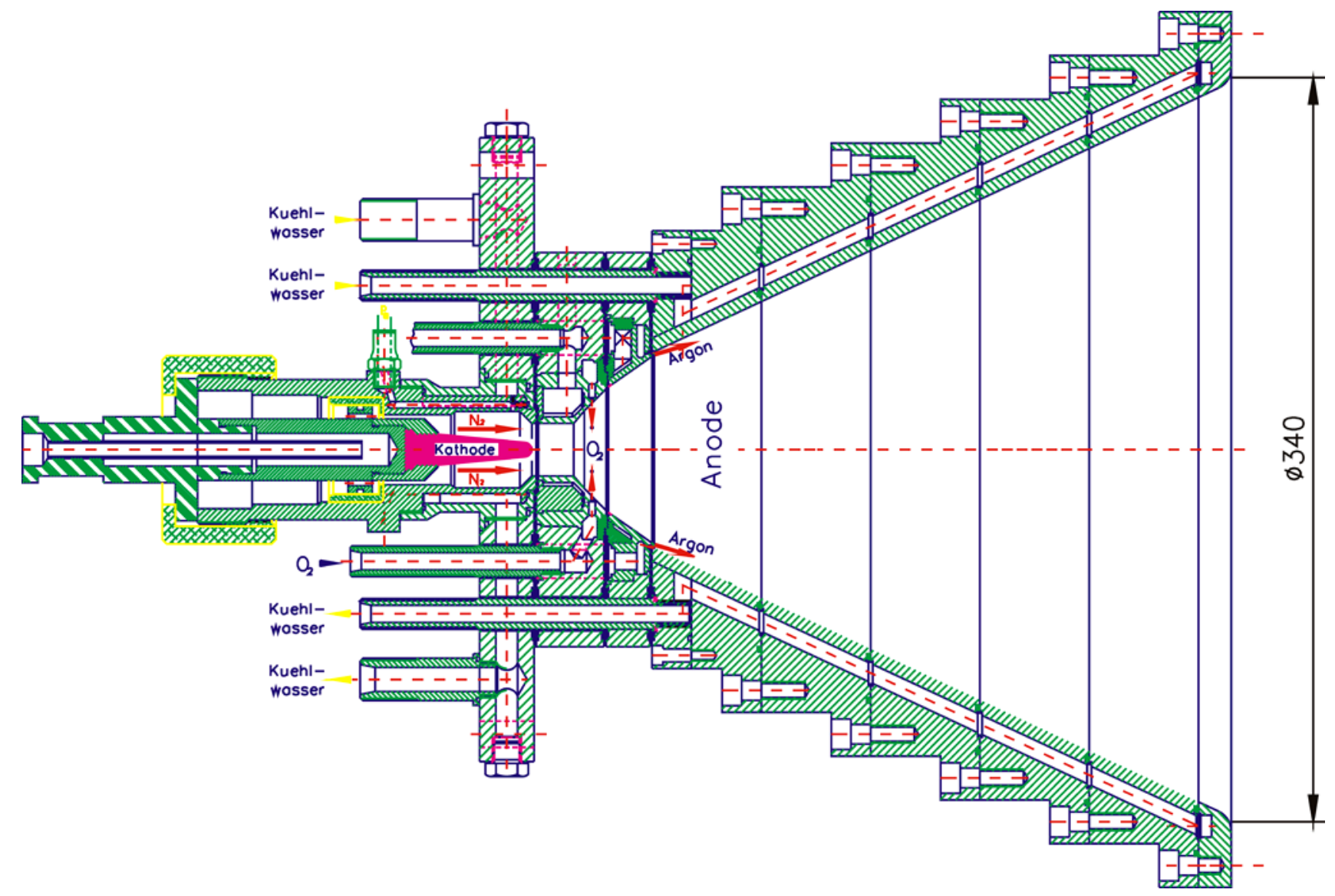

Fig. (8). Magnetoplasmadynamic generator RD7.

campaign and, just recently, for the test of the PARES (International Space Station Payload Retrieval System) nose structure.

For the tests of the $\mathrm{SEPCORE}^{\circledR}$ material the following requirements were met:

- $\quad$ The set-up was $0.4 \mathrm{~m}$ in diameter and equipped with a set of thermocouples. The measurements were combined with pyrometer and 2-dimensional CIDCamera measurements.

- Within the campaign pre-tests using an adequate heat flux probe were performed. The probe itself was equipped with Gardon Gages and Pitot pressure bores. A maximum heat flux of $10 \mathrm{MW} / \mathrm{m}^{2}$ was achieved.

The plasma generator conditions were set to $3,75 \mathrm{kA}$ and $8 \mathrm{~g} / \mathrm{s}$ mass flow rate (Nitrogen/Oxygen) resulting in a voltage of $133 \mathrm{~V}$ and an electrical power of $0,496 \mathrm{MW}$. At a distance of $\mathrm{x}=238 \mathrm{~mm}$ where the measurements were performed, a total pressure of $850 \mathrm{~Pa}$ was measured. Ambient pressure was $20 \mathrm{~Pa}$. Fig. (9) shows a photograph during the material test.

During the pre-test, the radial heat flux distribution was measured. Analogous measurements were performed with thermo-couples during the material test at different reference positions of the heat shield material. The overall experimental and pre-test analysis results allow for the statement that such a test condition may be used as a reference test case within the European ablation working group [25].

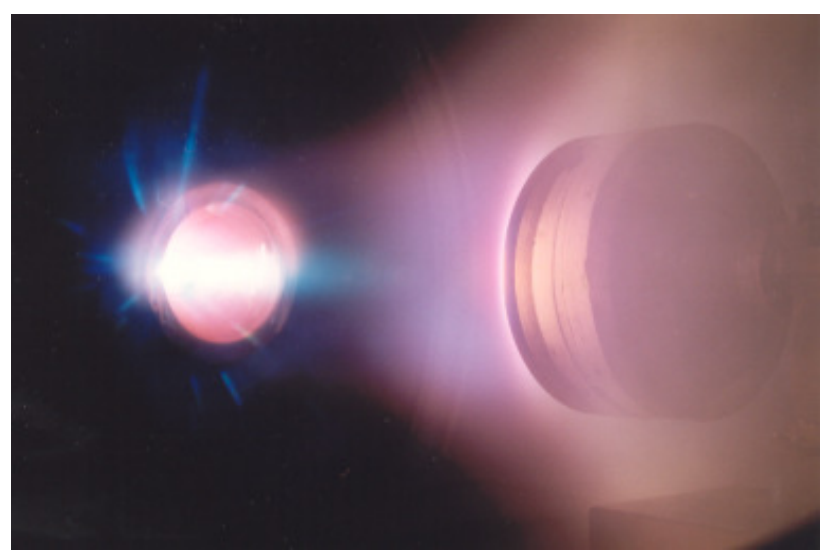

Fig. (9). Magnetoplasmadynamic generator RD7 in operation during $10 \mathrm{MW} / \mathrm{m}^{2}$ large sample test.

Depending on the distance of the heat flux probe to the plasma generators nozzle plane heat fluxes between $1 \mathrm{MW} / \mathrm{m}^{2}(\mathrm{x}=1 \mathrm{~m})$ and $10 \mathrm{MW} / \mathrm{m}^{2}(x=0,238 \mathrm{~m})$ were achieved.

In a first estimation this leads to local specific enthalpies between 85 and the order of several $100 \mathrm{MJ} / \mathrm{kg}$. The latter 
value may appear to have been senseless with respect to a typical re-entry condition: However, this value was needed to create an adequate radial heat flux profile along the $400 \mathrm{~mm}$ material sample. With this result it becomes conceivable that adequate local specific enthalpies for a giant planet entry could be achieved by using hydrogen/helium as working gases under a similar facility condition. Accordingly, as in the case of the aforementioned air condition the corresponding heat fluxes become substantially higher if one of the smaller probe designs is used.

\section{INDUCTIVELY HEATED FACILITIES}

Detailed information on inductively heated plasma wind tunnels can be found in [26]. During the past eight years the facility PWK3 has been qualified for both air and carbon dioxide flows. In addition, extensive investigations combining single gas tests (oxygen, nitrogen) with models dedicated to research work in the field of oxidation regimes and catalysis were performed [11].

Besides pure carbon dioxide flows also mixtures with the appropriate amount of nitrogen $(3 \%)$ were also investigated [22]. Additionally, a powder feeder (Metatherm ${ }^{\circledR}$, belonging to the Steinbeis Transfer Center Plasma and Space Technology) was used in order to insert representative dust powders into the plasma source [21, 22]. The overall function of the plasma facility is described in detail in reference [26]. Fig. (12) shows a photograph of the facility with some of the measurement techniques related to the characterization of the plasma source.

The vacuum chamber is about $2 \mathrm{~m}$ in length and $1.6 \mathrm{~m}$ in diameter. Optical accesses enable the investigation of the plasma. The flat lid of PWK3 (left side chamber) is equipped with the IPG (Inductively Heated Plasma Generator) and the external resonant circuit consisting of the capacitors with the connection to the IPG coil. The vacuum system which is described two sections above.

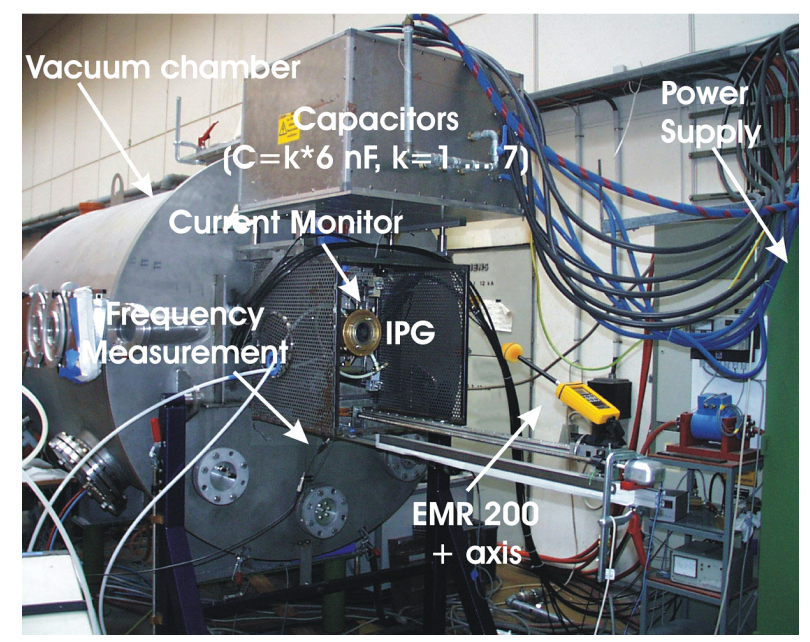

Fig. (10). PWK3 facility.

The obtained results in reference [22] appear to be promising as high enthalpy $\mathrm{CO}_{2}$ plasma tests using powder injection were carried out successfully. It was shown that steady state operation with $\mathrm{CO}_{2}$ plasma flows accompanied by high heat fluxes are feasible. Comparative tests were performed with and without additional iron oxide powder injection. Both heat flux measurements and Pitot pressure measurements resulted in significant differences between the tests with and without dust. The heat flux was measured on an iron oxide surface such that it can be compared to the tests with powder. Due to the higher heat fluxes with iron oxide powder it is clear that the behaviour of heat shield material under entry conditions with dust has to be investigated more intensively. Within an ESA funded campaign reference conditions with pure carbon dioxide are identified. Here, further optical measurement techniques and powder injection is planned in the near future.

One major problem is the discrepancy between the velocity of the particles and the velocity of the plasma. If the particle velocity is roughly analysed using a one-dimensional approach one gets the particle velocity $\mathrm{u}_{\mathrm{p}}$ :

$u_{p}=u-\left(\frac{1}{u-u_{p 0}}+\frac{3}{4} C_{d} \frac{\rho}{\rho_{p}} \frac{t}{d_{p}}\right)^{-1}$.

For the distance $\mathrm{x}$ that is travelled through by the particle one gets:

$x=u t-\left(K^{*}\right)^{-1} \ln \left(1+K^{*} u t\right)$.

Here, $\mathrm{K}^{*}$ is $3 / 4 \cdot C_{d} \cdot \rho / \rho_{p} \cdot 1 / d_{p}$. The parameter $\mathrm{u}$ is the plasma velocity, $\mathrm{u}_{\mathrm{p} 0}$ the particle velocity at $t=0 \mathrm{~s}, \mathrm{C}_{\mathrm{d}}$ is the friction coefficient of the particles, $\rho$ is the plasma density, $\rho_{p}$ the particle density and $d_{p}$ the particle diameter. The overall assumptions for the derivation are severe. However, to get a first insight the algebraic equations may be feasible for further recommendations. Equation 26 has $u_{p}=u$ as limit for increasing time t, a similar behavior, of course, applies to equation 27 regarding the behavior of $u_{p}$ over the distance $x$ if the equation is combined with equation 26, see Fig. (11). Here, typical values were taken for the plasma condition: $u=2 \mathrm{~km} / \mathrm{s}, \quad u_{p 0}=0 \mathrm{~km} / \mathrm{s}, \quad \rho=0.136 \mathrm{~g} / \mathrm{m}^{3} \quad(T=10 \mathrm{kK}$, $p=1 \mathrm{kPa}$ ), see also [26], $\mathrm{C}_{\mathrm{d}}$ was calculated via the Reynolds number $\left(\rightarrow\right.$ viscosity $\left.1,3610^{-4} \mathrm{~Pa} \mathrm{~s}\right), \rho_{\mathrm{p}}$ the particle density and $\mathrm{d}_{\mathrm{p}}$ the particle diameter. Here, $5.2 \mathrm{Mg} / \mathrm{m}^{3}$ and $1.5 \mu \mathrm{m}$ (Mars Exploration Rovers) were taken for the iron oxide based dust.

Under the conditions $u_{p}$ reaches $83 \%$ of the plasma velocity within the first $300 \mathrm{~mm}$ which is about the length of the plasma containment of the inductively heated plasma generator IPG3. However, plasma velocity is not constant nor it is $2 \mathrm{~km} / \mathrm{s}$ in the plasma containment. Nevertheless, the equations and the figure make some aspects transparent that may enable an increase of particle velocity:

- A technology enabling an initial velocity $u_{p 0}$ for the particles may be supportive.

- It is obvious that it is necessary to have a length of acceleration in combination with the guarantee of still having adequate plasma conditions at the point of interest.

- The plasma velocity should be fast in terms of the representation of a Mars entry.

- Simultaneously, adequate plasma densities are desirable as the ratio $\rho / \rho_{p}$ directly influences the particle's acceleration. 


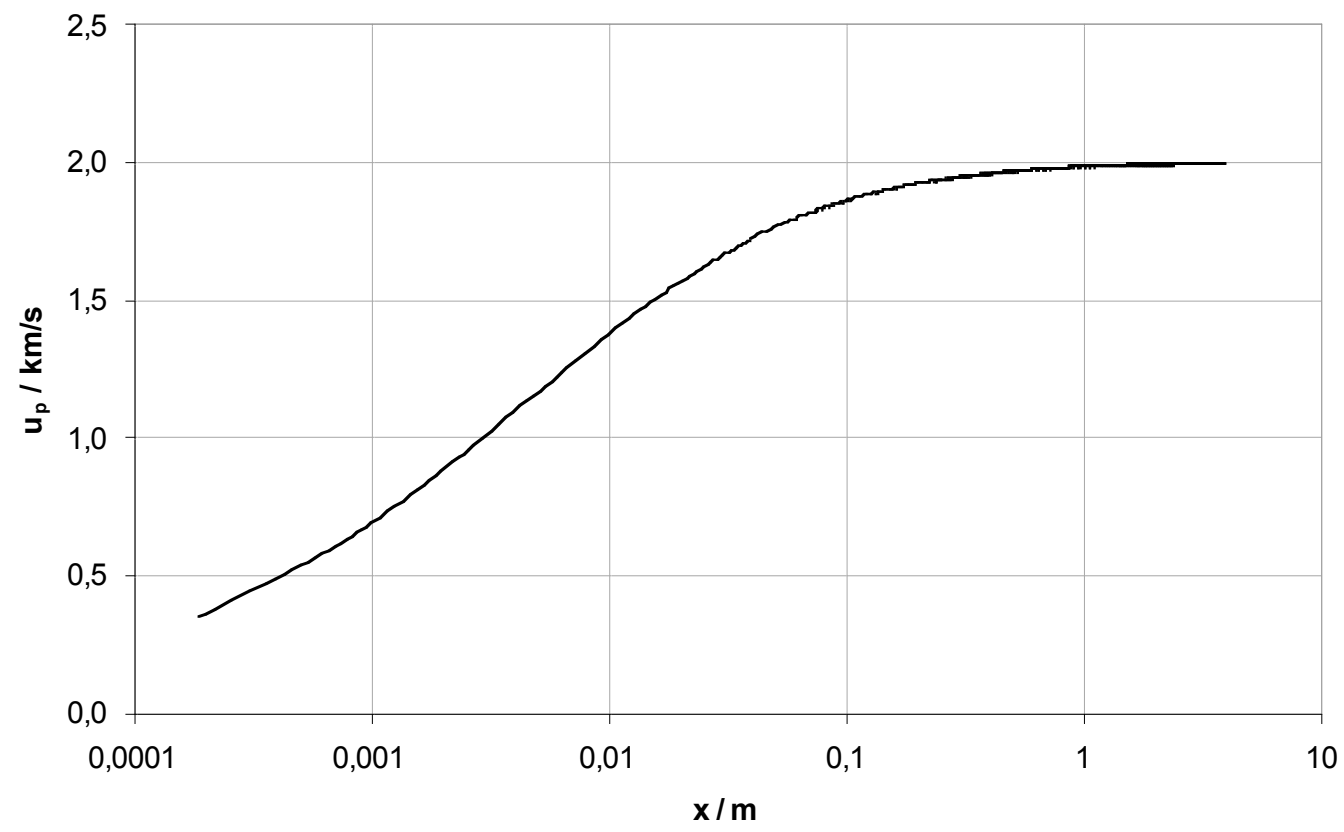

Fig. (11). Iron oxide particle velocity over flight distance $x$ in a one-dimensional plasma.

\section{IRS FACILITY CONCEPTS FOR HIGH ENTHALPY ENTRIES}

A variety of facilities to investigate high enthalpy entries is feasible. In principal, two facility working fields can be imagined: One consists of the reproduction of integral parameters such as e.g. the high mass specific enthalpies, the other consists of the provision of experimental infrastructures that allow the assessment of basic investigations such as e.g. in the field of radiation.

\section{Hybrid Concept for Generation of High Enthalpy Hydrogen Flows}

Hybrid systems appear to be promising as they can incorporate the different requirements needed for the specific missions on the basis of the advantages the single plasma systems have. Correspondingly, different hybrid systems are in discussion. At the University of Tokyo e.g. a combined laser / induction driven plasma process to cover the needed heat fluxes in combination with adequate pressures for Venus entries is being developed [27].

The hybrid system TIHTUS (Thermal-Inductive Hybrid Thruster of University of Stuttgart) has been developed for in-space propulsion [28]. The concept of TIHTUS is to heat the cold gas layer of an arcjet plume using induction heating. Therefore, the IPG3 has been applied as the second stage of a water-cooled thermal arcjet (see Fig. 14). The plasma jet emerging from the arcjet is expanded into the discharge tube, where it is inductively heated [26].

While an arcjet plume has high specific enthalpy and flow velocity in its core, theses characteristics are combined with the presence of steep radial property gradients. Meanwhile, the IPG is used as an afterburner since in induction heating, due to the skin effect, the power is coupled into the plasma at near-coil position, i.e. into the cold gas layer of the arcjet plume. Thus, an almost homogeneous profile of the plume characteristics can be achieved.

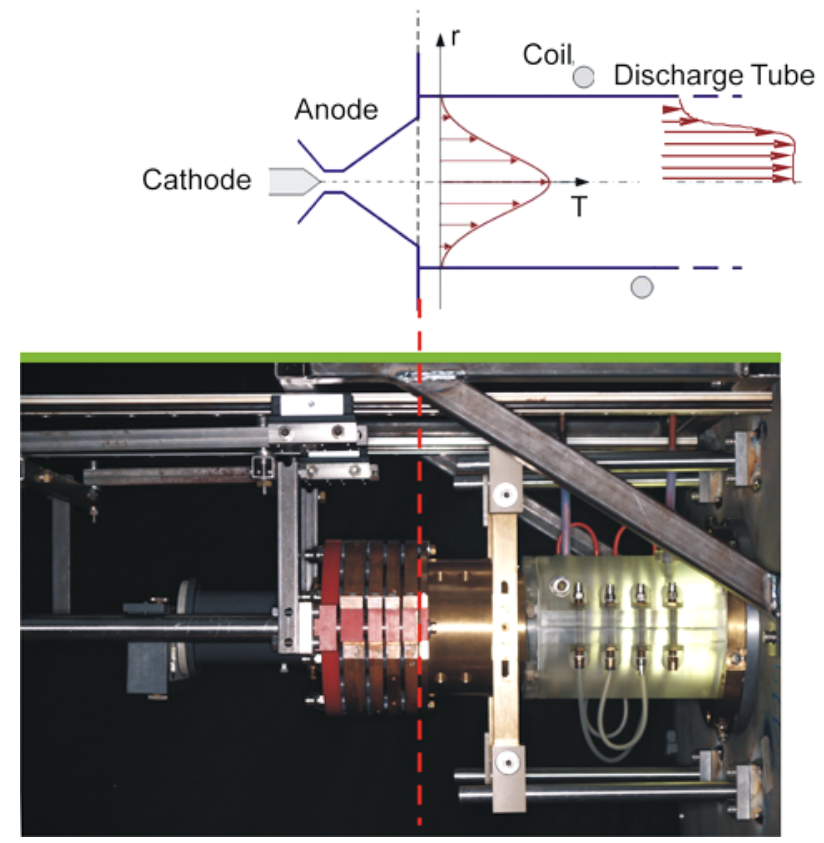

Fig. (12). Schematic (top) and photograph of TIHTUS.

Since hydrogen is used for the propulsion system TIHTUS, the system can be easily adapted for the entry simulation into the giant planet atmospheres.

The first stage is a $100 \mathrm{~kW}$ thermal arc-jet and it can be operated at mass flows from 100 to $600 \mathrm{mg} / \mathrm{s}$. The inductively heated stage is supplied by $180 \mathrm{~kW}$ radiofrequency power supply at frequencies ranging from 0.5 to $1.5 \mathrm{MHz}$. The IPG has already been operated with as little as $120 \mathrm{mg} / \mathrm{s}$ hydrogen. Hence, $280 \mathrm{~kW}$ of electric power are applicable for $200 \mathrm{mg} / \mathrm{s}$ of hydrogen mass flow. Assuming a 
thermal efficiency of only 0.7 , this leads to $980 \mathrm{MJ} / \mathrm{kg}$. such that a Jovian entry simulation may become possible.

\section{Instationary Concepts for the Generation of High Enthalpy Hydrogen Flows}

The reduction of test time is a classical approach and could allow for the generation of plasmas at sufficiently high specific enthalpies.

Within a cooperation between IRS, EADS (European Aeronautic Defence and Space Company), MTU (originally the abbreviation for "Motoren- und Turbinen-Union") and StC PRT the facility IMAX (IRS Magnetic Acceleration Experiment) was built up aiming for plasma peening and plasma de-coating processes in the field of material / surface treatment [29]. The facility can create power densities in the range of $\mathrm{GW} / \mathrm{cm}^{2}$. However, this can be achieved only by operating the facility in a pulsed mode such that the potential simulation is not in a steady state. The present design phase resulted in a plasma gun capable of delivering an incident power density of up to $2 \mathrm{GW} / \mathrm{cm}^{2}$ in less than $1 \mu \mathrm{s}$ on a target surface. The facility has a bank of 22 high-energy, low-inductance capacitors in the back and its electrodes located in the centre of the front flange.

Fig. (13) shows the accelerator and the vacuum facility. The system has recently been qualified for operation up to capacitor bank voltages of $20 \mathrm{kV}$.

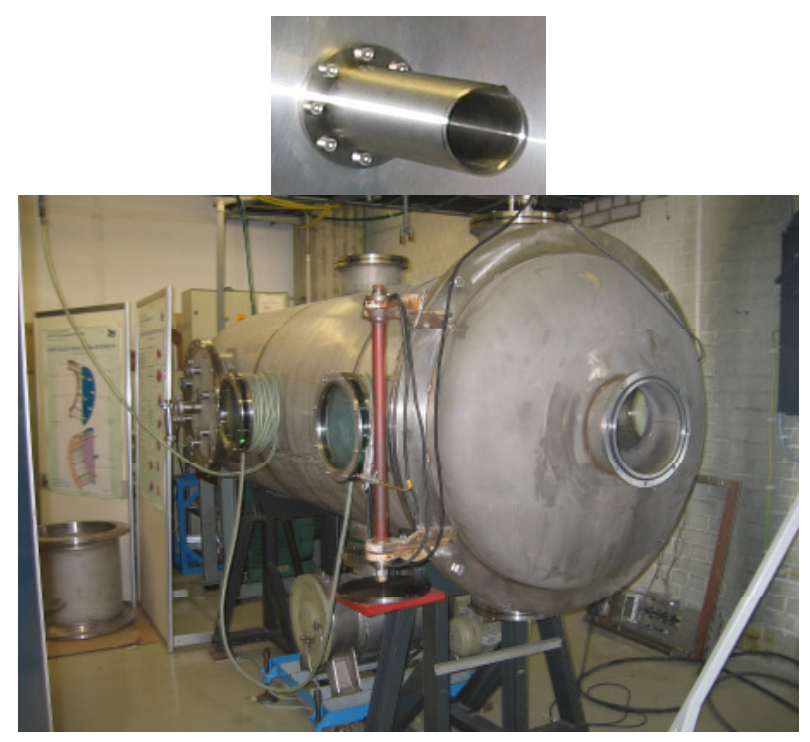

Fig. (13). Plasma accelerator and vacuum system.

\section{Concepts for High Pressure Facilities}

In order to develop a high pressure, high enthalpy facility a review of the existing facilities can be used as starting point $[4,15,21]$. Fig. (14) shows a schematic of existing concepts including the possible pressure regimes and enthalpy regimes. As can be seen, there is currently only one possibility to test the foreseen experimental vehicles, which is the constricted arc heater concept. However, for years, the problem using such devices is that the plasma generating process necessitates using copper electrodes [2].
Here, a Y-Concept could be the solution, see Fig. (15). Bringing together two arcjet generators of the same type brings the advantage of higher pressure while the thermal loads for the generator remains the same. In fact, this is only consequently thinking the hybrid concept, i.e. if stages are arranged in a row (TIHTUS), stages can also be arranged in parallel [4].

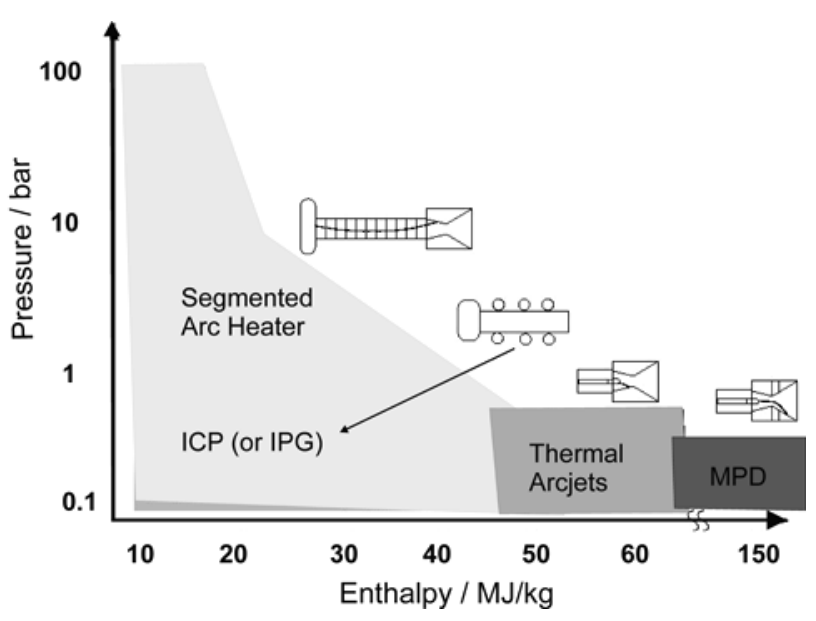

Fig. (14). Pressure Enthalpy sketch for Arc Heaters and inductively heating plasma devices (steady state facilities; ICP is Inductively Coupled Plasma).

\section{CONCLUSIONS}

The need for new advanced plasma simulation facilities for future scientific missions was motivated by extending the model of Allan and Eggers with respect to the inclusion of radiation heat fluxes and total heat fluxes that can be used as a means to derive initial first information on the thermal protection system mass fraction. With the extended model atmospheric entry parameters can be derived for ballistic capsules. However, to represent the radiation heat flux which is significant for hyperbolic reentries the model was extended by the radiation heat flux. In addition, the integrals for the integral heat loads were derived and solved. This provides the potential to assess parameters relevant within the test philosophy such as e.g. the test duration while having a material sample exposed e.g. under maximum heat flux conditions to the plasma. Therefore, a simplified tool is available to analyze test parameters from the mission relevant parameters.

Correspondingly, on a basis of existing data that were compiled from other sources the derived equations can be used to estimate the required TPS mass fraction e.g. for a Jovian entry. The consideration of the material availability and the research status allow for two statements: Materials for such missions as the aforementioned are rare and there is the need to develop and qualify new materials or existing materials for new missions using adequate plasma facilities. From the analysis of the well-known SEPCORE ${ }^{\circledR}$ material test conditions it could be derived that the used IRS facility is capable for the simulating hyperbolic re-entries. The generation of conditions for the giant planets seems to be adequate regarding both the overall enthalpies and the working gases that are feasible from the heritage of the MPD plasma sources (hydrogen as propellant!). 


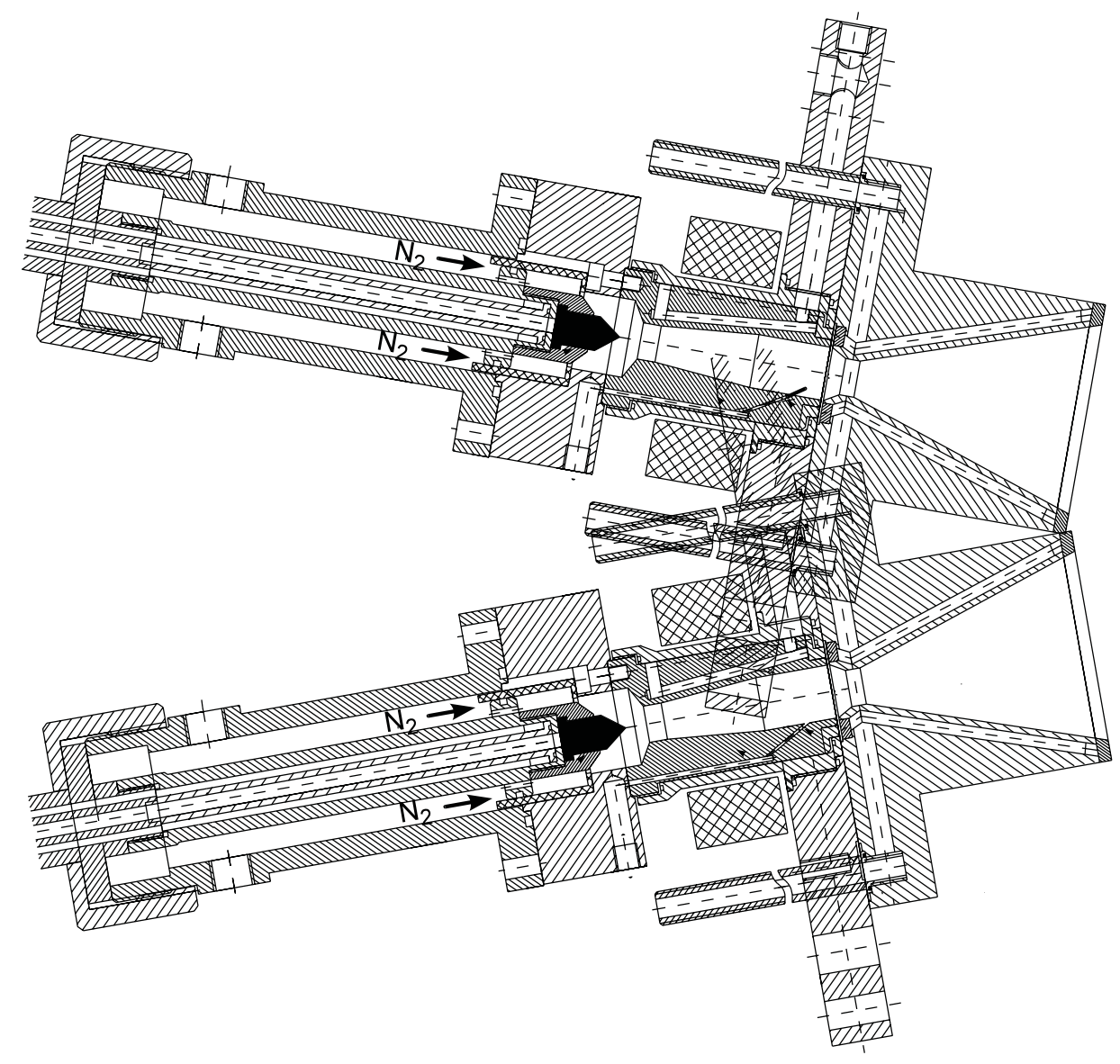

Fig. (15). Concept for Y-Design of two arcjet generators.

For the inductively heated plasma sources the situation is different. Here, the optimization of the input power means an adaption of operational frequency which, hence, renders the situation more complex. However, there may the chance to come up with higher velocities for Mars dust particles as the particles can be inserted to the plasma container which in turn lengthens the acceleration distance for the particles.

The mission concepts planned, however, also have to consider rather high mechanical (deceleration) and pressure related loads, see the Eqs. (7) and (10). These equations evidently outline that the corresponding loads can be very high e.g. for entry missions at planets such as the giant planets. In addition, aerothermodynamic demonstrator capsules such as EXPERT (European experimental re-entry test-bed) are presently being developed. The corresponding trajectories necessitate conditions at high total pressures (up to $0.3 \mathrm{MPa}$ ). Here, the need for additional independent facilities is evident. Advanced constricted arc facilities and parallelized arc jets belong to the candidates that will be able to cope with this task.

For the simulation including the loads appearing with atmospheric entries at giant planets, however, new facilities may be used. The hybrid plasma system TIHTUS seems to be a promising candidate to simulate the enthalpy and the pressure situation during such entries. The system has just been qualified for steady state high enthalpy hydrogen operation. A further candidate for such investigations is related to pulsed self-field MPD plasmas. A facility has been built up at IRS for terrestrial applications and is being qualified for the required powers.

A survey of plasma wind tunnel and shock tube facilities worldwide is given in reference [30]. Here, facilities producing moderate enthalpies such as thermal arcjets were considered, too. However, steady state facilities generating fairly high local specific enthalpies as they e.g. occur for hyperbolic reentries or atmospheric entries at the giant planets are rather rare and were included in the aforementioned reference.

\section{REFERENCES}

[1] Laub B, Venkatapathy E. Thermal protection system technology and facility needs for demanding future planetary missions. International workshop on planetary probe atmospheric entry and descent trajectory analysis and science. Lisbon: Portugal, 6-9 October 2003.

[2] NASA Engineering and Safety Centre (NESC). Independent Technical Assessment of Cassini/Huygens Probe Entry, Descent and Landing (EDL) at Titan, May 2005.

[3] Röck W. Simulation des eintritts einer sonde in die atmosphäre des saturnmondes titan in einem plasmawindkanal, dissertation (in German), Institut für Raumfahrtsysteme, Universität Stuttgart, 1999.

[4] Winter M, Herdrich G. Spectroscopic observation of the STARDUST Re-Entry in the Near UV, AIAA-2007-4050, Universität Stuttgart, Stuttgart, Germany, to be presented at $37^{\text {th }}$ AIAA Fluid Dynamics Conference and Exhibit, Miami, Florida, USA, June 2007. 
[5] Park C. Stagnation-point radiation for apollo 4 - a review and current status. $35^{\text {th }}$ AIAA Thermophysics Conference, Anaheim, CA, 11-14 June 2001.

[6] Wright M, Loomis M, Papadopoulus P. Aeorothermal analysis of the project fire II afterbody glow. $35^{\text {th }}$ AIAA Thermophysics Conference, Anaheim, CA, 11-14 June 2001.

[7] Lees L. Laminar heat transfer over blunt-nosed bodies at hypersonic flight speeds. Jet Propul 1956; 26(4): 259-69.

[8] Tauber ME, Sutton K. Stagnation point radiative heating relations for earth and mars entries. J Spacecr Rockets 1991; 28(1): 40-2.

[9] Detra RW, Hidalgo H. Generalized heat transfer formulas and graphs for nose cone re-entry into the atmosphere. ARS J 1961; 31: 318-21.

[10] Howe JT, Pitts WC, Lundell JH. Survey of the supporting research and technology for the thermal protection of the galileo probe. Paper AIAA-81-1068, $16^{\text {th }}$ Thermophysics Conference Palo Alto, CA, June 23-25, 1981.

[11] Herdrich G, Auweter-Kurtz M, Fertig M, Löhle S, Pidan S, Laux T. Oxidation behaviour of sic-based thermal protection system materials using newly developed probe techniques. J Spacecr Rockets 2005; 42(5): 817-24.

[12] Allan HJ, Eggers AJ. A study of the motion and atmospheric heating of missiles entering the Earth's atmosphere. NACA Technical Note 4047 Ames Aeronautical Laboratory, Moffett Field, CA, Oct 1957.

[13] Herdrich G. Extension of existing simple models to describe atmospheric entries- a link to tps design of capsules. Internal report IRS-07-IB5, Universität Stuttgart, Institut für Raumfahrtsysteme, May 2007.

[14] Ong Ch, Bieber BS, Needham J, et al. Planetary probe entry, descent, and landing systems: technology advancements, cost, and mass evaluations with application to future titan exploration missions. Georgia institute of technology, University of North Dacota, Rice University, Houston, California Institute of Technology, Pasadena, Jet Propulsion Laboratory, Pasadena, CA, Paper No. GT-SSEC.F.1, $1^{\text {st }}$ Annual Space Systems Engineering Conference, Atlanta Georgia, November 8-11, 2005.

[15] Young RE, Participants of the Entry Probe Workshop, Summary of the Boulder Entry Probe Workshop, Boulder, Colorado, USA, April 2003.

[16] Johnston IA, Weiland M, Schramm JM, Hannemann K, Longo J. Aerothermodynamics of the ARD - Postflight numerics and shocktunnel experiments, AIAA-2002-407, AIAA Aerospace Sciences Meeting and Exhibit, 40th, Reno, NV, Jan 14-17, 2002.

[17] Burkhardt J, Fertig M, Früholz H, Herdrich G, Koppenwallner G, Müller-Eigner R. Flugauswertung der MIRKA-Mission, Abschlußbericht IRS-98P16 (in German), DLR Förderkennzeichen 50 IO 9821, Universität Stuttgart, Institut für Raumfahrtsysteme 1998.
[18] Fertig M, Modellierung reaktiver Prozesse auf SiliziumkarbidOberflächen in verdünnten Nichtgleichgewichts-Luftströmungen, Dissertation (in German), Inst. für Raumfahrtsysteme, Universität Stuttgart, Germany, URN:urn:nbn:de:bsz:93-opus-24683, URL: http://elib.uni-stuttgart.de/opus/volltexte/2005/2468/, 2005.

[19] Green M J, Davy WC. Numerical simulation of experiments in the giant planet facility, ames research center, NASA, Moffett Field, California, AIAA-1979-1102, Thermophysics Conference, 14 ${ }^{\text {th }}$, Orlando, Fla., June 4-6, 1979.

[20] Park CH, Lundell JH, Green MJ, Winovich W, Covington M A. Ablation of carbonaceous materials in a Hydrogen-Helium arcjet flow. NASA Ames Research Center, Moffett Field, California. AIAA J 1984; 22: 10.

[21] Herdrich G, Auweter-Kurtz M, Endlich P. Mars entry simulation using the inductively heated plasma generator IPG4, Engineering Note. J Spacecr Rockets 2003; 40(5): 690-4.

[22] Endlich P, Auweter-Kurtz M, Herdrich G, Laure S. Simulation of mars entry conditions including dust particles. Proceedings of the $3^{\text {rd }}$ International Symposium Atmospheric Reentry Vehicles and Systems, Arcachon: France, March 2003.

[23] Herdrich G, Löhle S, Auweter-Kurtz M, et al. IRS ground-testing facilities: thermal protection system development, code validation and flight experiment development, AIAA Paper 2004-2596, 24 ${ }^{\text {th }}$ Aerodynamic measurement technology and ground testing conference, OR, June 28 - July 1, 2004.

[24] Auweter-Kurtz M, Fertig M, Herdrich G, et al. Entry experiments at IRS - In-flight measurement during atmospheric entries. $53^{\text {rd }}$ IAC, Houston, TX, USA, 2002. Space Technol J 2003; 23(4): 21734.

[25] Lacoste M, Barreteau R, Broque B. Sustainable C-phenolic ablative material for the ariane 5 SRM motor and application to TPS for entry probes. $5^{\text {th }}$ European workshop on thermal protection systems and hot structures May 2006.

[26] Herdrich G, Petkow D. High enthalpy, water-cooled and thinwalled ICP Sources: Characterization and MHD-optimization. J Plasma Phys 2007; 74(3): 1-39.

[27] Matsui M. Department of advanced energy. University of Tokyo, personal communication, May 2007.

[28] Böhrk H, Petkow D, Herdrich G, Auweter-Kurtz M, Kurtz H. Arcjet stage investigation and inductive hydrogen heating in the ATTILA engine. Proceedings of the 29th International electric propulsion conference Nov 2004.

[29] Auweter-Kurtz M, Herdrich G, Laure S, Wagner HP. Plasma source development for technical applications at IRS, VAC2970, 73/3-4. 2004; pp. 309-16.

[30] Lu FK. Advanced hypersonic test facilities. In: Marren, DE, Ed. Progress in astronautics and aeronautics series. USA: AIAA 2002; Vol. 13: p. 659.. 